\title{
Supplemental Materials For Database Management System Knowledge And Skills In The Accounting Information Systems Course
}

Ceil Moran Pillsbury, (Email: ceil@uwm.edu), University of Wisconsin-Milwaukee Ting J. Wang, (Email: TJWang@uwm.edu), University of Wisconsin-Milwaukee

\begin{abstract}
Much attention has been paid to the issue of enhancing students' understanding of the increasing role of database systems in accounting practice and integrating the modeling/operational aspects of such systems into the classroom. Recent surveys indicate that a number of Accounting Information Systems (AIS) professors are expanding their coverage of database topics, albeit some are only doing so on a more cursory basis. This paper reviews the changing nature of database education in AIS classes and provides supplemental active learning instructional aids to enhance the conceptual database coverage in AIS texts. The materials provide Systems professors who have time/resource constraints or limited formal training on database systems with an easy to learn and easy to adopt set of Access 2000 exercises. Students implement a pre-designed relational data model and experience the creation and use of database tables, forms, queries and macros. The materials build on the data set present in the widely used Systems Understanding Aid by Arens and Ward (1995), but it is not necessary to use them in conjunction with that case.
\end{abstract}

\section{Introduction}

tarting in 1986, and during the ensuing decade, there were repeated calls from the accounting profession, the American Accounting Association and many academics to reorient accounting information systems education to produce more technologically literate graduates (AICPA 1988; AAA 1986; AECC 1990). In particular, the issue of enhancing students' understanding of the increasing role of database systems in accounting practice and integrating the modeling and operational aspects of such systems into the classroom received much focus (Heagy and McMickle 1988; Stocks and Romney 1987; Davis and Leitch 1988). This attention occurred even before the pervasiveness of enterprise resource planning (ERP) packages and e-commerce applications, both of which are commonly intertwined with a relational database backend structure. Thus, it comes as no surprise that a widening gap existed between the demand for accounting program graduates with DBMS training and the supply of graduates with adequate preparation in this area. Heagy and McMickle (1988) found that the importance of DBMS training was the topic with the second largest difference in ranking between accounting practitioners--ranked $20^{\text {th }}$-and academics--ranked $48^{\text {th }}$. Six years later, in a study jointly sponsored by the Institute of Management Accountants and the Financial Executives Institute, high-level accounting and financial executives ranked information systems design as one of the five "most underprepared" topics in accounting education (Siegel and Sorensen 1994). At the same time, another report showed that organizations are focusing on developing accounting systems in order to integrate their internal and external reporting capabilities and provide accounting information to users in on-line databases (Elliott 1994).

Readers with comments or questions are encouraged to contact the authors via email. 
Despite the increased demand for graduates skilled in database knowledge and use, preparation in the area continued to be inadequately emphasized in undergraduate accounting programs. Calderon, Olsen and Conrad (1996) found that large numbers of AIS instructors were not covering fundamental concepts and topics in the area of database management systems.

Moreover, the level of coverage was relatively low among those instructors who did incorporate database concepts and topics into their AIS course. A number of reasons have been posited as to why DBMS training may be inappropriately emphasized in the undergraduate accounting programs. First, many AIS instructors, perhaps more than 50\%, have very little formal training in the information systems area or are self-taught (Calderon, et al. 1996). Second, Garceau and Bloom (1997) found that faculty members are hesitant to embrace the use of newer technology because of the time-consuming effort required to prepare classroom applications, lack of financial resources, and limited incentives in the current reward structure. Also, many authors have noted the incredible myriad of topics to be covered in the typical one-semester AIS course offered by many schools and the difficulties of doing so. A partial list of potential topics includes traditional AIS architecture, systems documentation techniques, data processing, information technology concepts, data modeling and database design, systems analysis and design, systems implementation issues, commercial accounting software, transaction processing accounting cycles, internal controls, computer controls, and electronic commerce. As a result of the importance of such topics, many believe that tradeoffs have been made on coverage of essential DBMS concepts and topics, especially by instructors with little formal training (Calderon, et. al. 1996; Bothrick 1996; Jensen 1992). Finally, the lack of sufficient coverage of DBMS in the AIS textbooks may have also contributed significantly to the problem, since research has shown the availability of textual materials is of major importance to AIS professors in topical selection (Theuri and Gunn 1998).

There is, however, reason to believe that AIS curricula are being constructively adjusted. Recent years have witnessed the response of accounting information systems (AIS) textbook authors and some systems professors to these calls for curriculum adaptation. Of particular note, many accounting information systems authors have responded to the demand for increased attention to database concepts and topics. Several new AIS texts have entered the market which address accounting systems from the relational database view of accounting (Hollander, et. al. 2000; Murthy and Groomer 2000; Perry and Schneider 2000). In addition, a number of revisions of more established texts have also added significant database components (e.g. Gelinas, et. al. 1999). Given this increase in textual coverage, we would expect to observe greater coverage of database topics in the curriculum. Indeed, several recent studies indicate Systems professors are paying more attention to database topics, albeit some are only providing a conceptual overview (Hermanson, et. al. 1999; Bryant, et. al. 1999; Theuri and Gunn 1998).

\section{Purpose}

The purpose of this paper is to present educational materials to supplement the conceptual coverage of DBMS concepts and topics in the AIS undergraduate accounting course. The authors developed a series of DBMS assignments with simple, step-by-step directions that instructors can easily implement in the AIS course. The assignments are intended for instructors who lack the time or faculty reward structure to prepare DBMS application materials on their own or those who have little or no formal training in DBMS. For those professors wanting a more complex database project we refer you to Olsen (1999 and 2000).

The two common approaches to teaching the AIS course are 1) the traditional "textbook" or conceptual approach, and 2) an integrated course with "software-specific skill training" and accounting systems knowledge, i.e., combining textbooks with hands-on use of computers (Pillsbury and Saemann 1996; Pillsbury and Saemann 1997; Levitan 1988). Although there has been debate about the educational usefulness of including specific software training in the AIS course, more recent views have stated the importance of including a hands-on learning component (Borthick and Clark, 1987; New Accountant, 1992; Romney, et al. 1996). In particular, Stone, et al. (1996) found that adding skill-building training to the accounting curriculum was more effective than providing conceptual knowledge alone.

The authors believe that for students to really comprehend the importance and use of relational databases they need to experience the application of DBMS concepts, not just receive conceptual coverage of the topic in a textbook and lecture. Bonner (1999) supports the idea that student learning of complex skills requires teaching methods that promote active learning components. The purpose of our DBMS materials is to provide students with an 
active learning practical application of how a database works. The intention is not to make a student proficient in any particular DBMS software. Rather, it is important to emphasize the capabilities of database systems in general, not the intricacies of the particular software package utilized. This approach allows students to develop transferable skills that will not be limited to a particular package that may be outdated shortly. Our materials allow students to explore the basic features found in any database management system and to complete the work efficiently during a semester undoubtedly filled with other important material. The exercises are designed to reduce the amount of preparation time spent by instructors and minimize the amount of computer lab time required. The instructions are very complete and have been tested extensively by multiple professors over multiple semesters. Assignments can be done outside of class, although lab time is always desirable if feasible. Because students have hands-on exercises to illustrate the implementation of tables, forms, macros and queries, professors can refocus classroom time to discussion of database topics their students have more difficulty understanding such as normalization and cardinality.

The instructions sets are detailed. One problem with detailed instruction sets is that some students tend to follow the instructor's "click by click" directions without fully focusing on or understanding the processes involved (Pillsbury and Saemann 1997). In the materials developed by the authors, two approaches are incorporated to prevent the above problem. First, specific directions are given in the assignments but they are only given for one instance so that similar procedures have to be repeated in multiple similar cases. For example, in Assignment Three, students are required to create several macros but specific directions are only given about how to create the first one. This forces students to concentrate on understanding, not just following, the instructions and enhances students' understanding of the steps they are performing. Second, the query directions are often integrated with questions throughout the materials to make students stop and reflect on what they have done (e.g. see Assignment Four).

The authors used Microsoft Access 2000 to illustrate the applications of DBMS concepts and topics in the AIS course for three reasons:

- Access is the most popular and widely available DBMS package for Windows on the market. As compared to other DBMS software, accessibility is not a problem for instructors who are willing to incorporate the materials into the course and for the students who use them. In addition, virtually all students are familiar with Word and Excel and there is some transferability of these skill sets to the use of Access. An added advantage of Access is that many students have Office 2000 available already on their home computers.

- Access is an object-based software that features an intuitive graphic user interface (GUI). The GUI feature provides a user-friendly learning environment that makes learning DBMS easier for students--and for instructors who are either self-taught or have little formal training in DBMS.

- Access is used in many of the AIS textbooks that illustrate the applications of DBMS concepts and topics (Murthy and Groomer 2000; Perry and Schneider 2000; Romney and Steinbart 2000; Moscove, et al. 2001).

There are seven database objects in Access 2000: tables, queries, forms, reports, macros, pages, and modules. The materials presented in this paper consist of four assignments that reinforce the conceptual DBMS knowledge students acquire from the AIS texts and provide them with effective experience in actual DBMS use. Each assignment relates respectively to the development and use of four database objects--tables, forms, macros and queries. We also have assignments available now, but which are not included in this paper, on more complex queries and reports. A description of the objectives accomplished in the four exercises follows:

\section{Assignment One Learning Objectives:}

Set up table structures and field properties

Identify primary keys and establish table relationships with foreign keys

Understand one-to-many and many-to-many relationships

Work with relationship tables (i.e., for a bridge entity)

Understand and enforce referential integrity

Read a REAL diagram 


\section{Assignment Two Learning Objectives:}

Create single and multiple-table forms

Enter data using forms

Insert an OLE object--a graphic logo in this particular assignment

\section{Assignment Three Learning Objectives:}

Create macros for automating procedures, e.g. to validate order input data

Create record navigation and operation buttons with and without keyboard shortcuts

\section{Assignment Four Learning Objectives:}

Develop simple queries sorting, listing and specifying criteria for data from single tables

Develop more complicated queries involving aggregate functions and using expression builder with linked tables

All assignments can be obtained directly from the authors or from the web site http://www.uwm.edu/ $\sim$ ceil/systems/assignments.html\#data. Answer keys are available to professors through email.

\section{Conclusions}

Companies are placing increasing reliance on database systems to meet the information needs of internal and external users. Given this trend and the incredible speed with which ERP, e-commerce, data warehousing, data mining applications have been adopted, it is little wonder that there are more and more calls for accounting graduates with knowledge of DBMS software and "hands-on" skills in its use (Messmer 1999; Williams 1999). These innovative database applications, along with the AICPA visioning process, competitive pressures, and the changing nature of doing business in a networked world, will undoubtedly accelerate the shift of many accountants from the role of exclusively preparing information to the roles of designers, managers and auditors of database systems (AICPA 1998; Olsen 2000).

The authors greatly appreciate the assistance of Owen Cherrington with this project. Also, we acknowledge the helpful comments of the participants of the ABR conference.

\section{Teaching Notes}

We use the Access assignments after having first presented conceptual coverage of database objects and the topic of normalization. We cover cardinality within the context of the E-R diagram presented in Assignment One (see Assignment One) and we discuss the nature of the assumptions made about the relationships. Students are able to easily grasp the concepts when looking at the diagram. We also use the opportunity to discuss what would happen to the E-R diagram if you changed the relationship assumptions based on different business models. For example, we assume that orders are handled by a team sales approach which would change the relationship between salesperson and order from one-to-many to many-to-many. We cover the concept of referential integrity when looking at the customer/order and supplier/item tables in the E-R diagram (this can be done with any of the one-to-many relationships).

We find the materials are suitable for a typical undergraduate accounting major. We do not have students develop their own entity-relationship (E-R) diagrams, they are given a pre-designed E-R diagram to use and interpret. Professors who want to increase the complexity of the assignment can easily do so by deleting the given diagram and requiring students to design their own E-R diagram. We also have more difficult query and report assignments available which are not included with this manuscript.

The vast majority of students complete the assignments without running into any difficulties other than normal software related issues. Completion times vary greatly. Some students complete the assignments in under two hours and some take more than eight. The average is in the range of three to four hours. Hints and emphasized text have been added throughout the instructions on issues which have occurred with previous students. Even so, it is worthwhile to make particular note of the following: 
Assignments One and Two: It is important to remind students that they need to set up the table relationships properly in Assignment One or they will run into referential integrity issues when entering their data into the tables using the forms in Assignment Two. Students who do set up these relationships improperly can simply redo Assignment One or the professor can elect to allow them to delete the referential integrity which will enable the student to enter the data. Also in Assignment One, students should be reminded to set up their primary keys as indicated in the table structures and not to allow Access to automatically assign one. In Assignment Two, students should be reminded to enter the data into the tables in the order given. This becomes very important for the multiple table forms because you need to enter the data for the one side of the relationship before entering the data for the many side of the relationship. Again, this avoids referential integrity issues that would be encountered if, for example, the student is trying to enter invoice information before setting up a related customer. Students who do not get the "form with sub forms" radial button for the multiple-table form did not set up the composite key properly in the order/item table.

Assignment Three: It is important to make sure that students understand that they are creating groups of macros-each of which will have several individual macros in it. Otherwise, they may end up with each button and macro on a separate form thereby defeating the purpose of the macros. Also, students should be reminded to use the database provided for Assignment Three.

This ensures that if the student made mistakes in Assignments One or Two that the errors do not carry over to Assignment Three.

Note: Instruction sets and Word and Database solutions sets are available on a password protected web site.

\section{References}

1. Arens, A., and D. Ward. 1995. Systems Understanding Aid, Armond Dalton Publications.

2. American Accounting Association (AAA). 1986. Committee on Contemporary Approaches to Teaching Accounting Information Systems. Sarasota, FL: AAA.

3. American Education Change Commission (AECC). 1990. Objectives of education for accountants: Position statement number one. Issues in Accounting Education (Fall): 307-312.

4. American Institute of Certified Public Accountants (AICPA). 1988. Education Requirements for Entry into the Accounting Profession. New York: AICPA.

5. American Institute of Certified Public Accountants (AICPA). 1998. CPA Vision: 2011 and Beyond. New York: AICPA.

6. Bonner, S. E. 1999. Choosing teaching methods based on learning objectives : An integrative framework. Issues in Accounting Education (February): 11-39.

7. Bothrick, A.F. 1996. Helping accountants learn to get the information managers want: The role of the accounting information systems course. Journal of Information Systems (Fall): 75-85.

8. Borthick, A. F., and R. L. Clark. 1987. Research on computing in accounting education: Opportunities and impediments. Issues in Accounting Education (Fall): 173-192.

9. Bryant, S. M., J.K. Weishar, and D. R. Fordham. 1999. A survey of accounting information systems programs in U.S. colleges and universities. The Review of Accounting Information Systems (Spring): 1-11.

10. Calderon, T. G., D.H. Olsen, and E. J. Conrad. 1996. Database coverage in the accounting information systems course. Journal of Accounting and Computers, Issue 12 (Spring). Published electronically by Southwestern Publishing at http://www.swcollege.com/acct/jac/jac12.html

11. Davis, J. R., and R. A. Leitch. 1988. Accounting information systems courses and curricula: new perspectives. Journal of Information Systems (Fall): 153-166.

12. Elliott, R.K. 1994. Confronting the future: Choices for the attest function. Accounting Horizons, 8(3): 106124.

13. Garceau, L.R., and R. Bloom. 1996-97. Technology in the undergraduate accounting curriculum. The Review of Accounting Information Systems (Winter): 51-62.

14. Gelinas, U. J., S.G. Sutton, and A.E. Oram. 1999. Accounting Information Systems, Fourth Edition, Cincinnati, Ohio: Southwestern.

15. Heagy, C.D., and P.L. McMickle. 1988. An empirical investigation of the accounting systems course: Academic practice versus practitioner needs. Issues in Accounting Education 3(1): 96-107.

16. Hermanson, D. R., M. C. Gill, and D. M. Ivancevich. 1999. Information technology in the undergraduate ac- 
counting curriculum. The Review of Accounting Information Systems (Fall): 1-9.

17. Hollander, A. S., E. L. Denna, and J. O. Cherrington. 2000. Accounting, information technology, and business solutions, Second Edition, Burr Ridge, IL: Irwin.

18. Jensen, R. L. 1992. Providing a relational database experience in the accounting information systems course. South-Western/Bentley Journal (Fall): 85-92.

19. Levitan, A.S. 1988. Using a data base management system in an accounting information systems course. The Journal of Information Systems (Spring): 73-78.

20. Messmer, M. 1999. The growing role of technology. Strategic Finance (December): 10-11.

21. Moscove, S. A., M.G. Simkin, and N. A. Bagranoff. 2001. Core concepts of accounting information systems. NY: John Wiley \& Sons, Inc.

22. Murthy, U., and S. M. Groomer. 2000. Accounting information system: A database approach. Cybertext: http://www.cybertext.com.

23. New Accountant. 1992. Forecasts (by a Coopers \& Lybrand spokesperson), 6.

24. Olsen, D. H. 1999. Accounting database design and SQL implementation. The Review of Accounting Information Systems, (Summer): 15-68.

25. Olsen, D. H. 2000. Accounting database design and SQL implementation revisited. The Review of Accounting Information Systems, (Spring): 53-64.

26. Perry, J. T. and G. P. Schneider. 2000. Building accounting systems with Access 2000, Cincinnati, OH: Southwestern Publishing.

27. Pillsbury, C. M., and G. C. Saemann. 1997. Using commercial accounting software to illustrate accounting information systems topics. The Review of Accounting Information Systems, (Spring): 1-35.

28. Pillsbury, C. M., and G. C. Saemann. 1997. More on using commercial accounting software to illustrate accounting information systems topics. The Review of Accounting Information Systems (Winter): 43-61.

29. Romney, M. B., J. O. Cherrington, and E. L. Denna. 1996. Using information systems as a basis for teaching accounting. Journal of Accounting Education (Spring): 57-67.

30. Romney, M. B., and P. J. Steinbart. 2000. Accounting information systems. Upper Saddle River, NJ: Prentice Hall.

31. Siegel, G., and J. E. Sorensen. 1994. What corporate America wants in entry-level accountants. New York: Institute of Management Accountants and The Financial Executives Institute.

32. Stocks, K. D., and M. B. Romney. 1987. The supply and demand for IS/MAS graduates. The Journal of Information Systems (Spring): 83-100.

33. Stone, D. N., V. Arunachalam, and J. S. Chandler. 1996. An empirical investigation of knowledge, skill, selfefficacy and computer anxiety in accounting education. Issues in Accounting Education (Fall): 345-376.

34. Theuri, P. M. and R. Gunn. 1998. Accounting information systems course structure and employer systems skills expectations. Journal of Accounting Education: 101-121.

35. Williams, D. 1999. Reporting with a purpose. CA Magazine (March): 45-47. 